\title{
Factors affecting children's involvement in asthma consultations: a questionnaire survey of general practitioners and primary care asthma nurses
}

\author{
*Amy C McPhersona, Sarah A Redsell ${ }^{b}$ \\ a Lecturer in Health Psychology, School of Nursing, University of Nottingham, UK \\ ${ }^{\mathrm{b}}$ Principal Research Fellow, School of Nursing, University of Nottingham, UK
}

Received 26th October 2007; revised 30th April 2008; accepted 11th May 2008; online 23rd July 2008

\begin{abstract}
Aim: To explore UK primary care healthcare practitioners' involvement of children in asthma consultations.

Method: Self-report questionnaires with both quantitative and qualitative sections were sent to 124 consenting general practices in seven Primary Care Trusts for completion by nurses and general practitioners (GPS).

Results: Some healthcare practitioners struggle to achieve concordance with children in consultations. Communication with children and their parents can be challenging, with parents acting as potential facilitators and barriers. Age and cognitive ability are perceived to be the most important factors affecting children's involvement in consultations.

Conclusions: Involving children in consultations is challenging and some practitioners have developed specific strategies to help them communicate. However, additional training may be needed to enable them to facilitate children's involvement.

(C) 2009 General Practice Airways Group. All rights reserved.

AC McPherson and SA Redsell. Prim Care Resp J 2009; 18(1): 15-20.

doi:10.3132/pcrj.2008.00040
\end{abstract}

Keywords asthma, involvement, children, participation, primary care

The full version of this paper, with online Appendices,

is available at www.thepcrj.org

\section{Introduction}

Many children with asthma experience school absence, restricted activity, hospitalisations and stress. ${ }^{1,2}$ A recent systematic review concluded that children with asthma who are actively involved in their treatment learn to cope with and control their condition more effectively. These children experience improved lung function, reduced school absence, increased self-efficacy and lower use of emergency services. ${ }^{3}$ There is also evidence that children (and their parents) want greater involvement in their healthcare. ${ }^{4}$ This is reflected in recent UK Government policy, which has set targets for improving children's involvement in their own healthcare. ${ }^{5}$

In the UK, the majority of asthma care takes place in the primary care setting. ${ }^{6}$ Ideally, consultations with general practitioners (GPs) and practice nurses/nurse practitioners should represent an opportunity for children to learn about their condition and develop an understanding of what they need to do to keep well. However, little empirical work examining children's involvement in their healthcare has been undertaken in the UK.? International studies of doctors' consultation behaviour with children, involving both acute and chronic health conditions, indicate that children's contributions to consultations are generally $\operatorname{low}^{8-10}$ and in some cases, non-existent. ${ }^{11}$ GPs seem prone to addressing the child only when physically examining them. ${ }^{10}$

Research suggests that in contemporary medical practice the dominant communication model is one of consultation between the clinician and parent as 'proxy'. ${ }^{12}$ Where children contribute to a consultation, it is primarily to provide information or engage with social conversation $n^{10,11,13}$ and

\footnotetext{
* Corresponding author: Dr Amy McPherson, B Floor Medical School, Queen's Medical Centre, Derby Road, Nottingham, NG7 2 UH, UK. Tel: +44 (0)1158230957 Fax: +44 (0)1158231211 E-mail: Amy.Mcpherson@nottingham.ac.uk
} 
reports suggest that doctors are unlikely to discuss management issues or medical information, even with older children and adolescents..$^{9,14}$ This practice is at odds with the considerable body of evidence that demonstrates that involvement of the child yields significant clinical and psychological benefits. ${ }^{1,3,15}$

The extent of a child's involvement in their consultation depends on both the practitioner's behaviour, and that of the parent and child. ${ }^{9}$ Parents can be responsible for both excluding and facilitating children's contributions to a consultation, ${ }^{10}$ and characteristics such as the child's age are influential; older children tend to demonstrate more active involvement than younger children, ${ }^{10,16}$ a trend that may reflect the clinician's own assumptions about age-related competence. ${ }^{17}$

In the UK, nurse-led asthma care can be found in many primary care facilities and evidence suggests that it results in positive outcomes. ${ }^{18,19}$ The significance of consultation style is, however, unknown; indeed, there is a paucity of published research into the ways in which health practitioners other than doctors interact with children during healthcare consultations.

This study uses a descriptive survey to elicit self-reports of consultation style and current practice from GPs and practice asthma nurses. It also seeks to identify their views about the factors that most influence the nature and extent of child involvement in asthma consultations. Therefore, the two research questions were:

1. How do healthcare practitioners view their communication style in consultations involving children with asthma?

2. Which factors do healthcare practitioners think affect the level of involvement of children in consultations?

\section{Methods}

\section{Sample}

Healthcare professionals (HCPS) at general practices located within seven Primary Care Trusts (PCTs) in the East Midlands region of the UK were invited to participate in the study. The PCTs were selected to cover a range of socioeconomic areas (including affluent/deprived, rural/urban, high/low minority ethnic population), although formal deprivation indices were not recorded.

\section{Inclusion/exclusion criteria}

Participants were required to be a) presently working in a general practice situated in one of the selected PCTs, and b) to have served a minimum of three months as either a GP or nurse practitioner/practice nurse.

\section{Measures}

A self-report survey was constructed by a health psychologist with experience of childhood asthma education and a nurse with expertise in consultation skills. Items were generated with reference to the existing literature on children's consultations. A paediatric respiratory nurse specialist, a primary care nurse with asthma training, and a respiratory paediatrician provided input and guidance on the questionnaire, and comments were obtained from members of the Primary Care Nursing Research Network - a UK-wide online discussion group. Comments on both the usability of the questionnaire and its content were incorporated into the final version - for example, tick boxes were included for ease of use, but more room was then provided for the practitioner to explain their response in more detail. In terms of content, one respondent suggested determining "the context of the care within the GP surgery, for example, does the practice operate a nurse-led service or combined GP/nurse clinic?". The issue of whether the HCP saw the child alone was also raised, which was also subsequently incorporated into the final survey.

The final agreed survey sought to record the following information:

- Provision of asthma care in the practice

- Respondent and patient demographic data such as age and gender

- Typical involvement of children in asthma consultations

- Factors perceived to dictate appropriate level of child involvement in asthma consultations

- Challenges in childhood asthma management

The questionnaire incorporated both quantitatative and qualitative elements. For example, practitioners were asked 'Which aspects of the consultation do you involve children in?' choosing from a range of options including assessment, diagnosis, inhaler technique etc. They were then asked to elaborate in their own words on how they attempt to involve the child in that aspect of the consultation. The survey questionnaire is shown in Appendix A, available online at www.thepcrj.org.

\section{Procedure}

Practices were invited to participate (or signal non-consent) by post. Practices who did not respond were sent copies of the survey for all practitioners to complete if they wished. Completion implied individual consent. Questionnaires were completed anonymously, although were marked with a code identifying the practice for administrative purposes. This code was unknown to those conducting the analysis. The study was approved by the local Research Ethics Committee and research governance permissions were obtained from the local PCTs.

\section{Analysis}

Numerical data were analysed using SPSS Version 14.0.1. Summary and descriptive statistics were calculated for frequency data. Ordinal data were analysed using nonparametric tests. Thematic analysis was performed on the free-text sections and key issues identified through coding and categorising the text. ${ }^{20}$ 


\section{Results}

\section{Response rates}

There were 159 eligible practices, 35 of whom withheld consent to participate. Forty-eight of the 124 remaining practices returned 120 completed questionnaires, giving a practice response rate of $38.7 \%$.

\section{Practice characteristics}

There was a median figure of four GPs and two nurses in responding practices. Asthma care was mostly delivered by a team of GPs and nurses (58\% of practices) and nurse-led clinics (38.7\%). Fifteen out of the 48 responding practices (31.3\%) ran dedicated asthma clinics.

\section{Respondent characteristics}

Completed questionnaires were received from 48 nurses and 69 GPs. Job description was missing from three questionnaires. All respondent nurses and 38/69 respondent GPs were female. The majority (95.4\%) of respondents were aged between 30 and 59 years; $49.2 \%$ had been working in their role for over ten years, with $20.8 \%$ working in the role for $5-10$ years and $30 \%$ for less than five years.

Respondents had been involved in children's asthma management for an average of 10 years (range 1-36 years), the majority (83.2\%) seeing between one and 10 children per month, with $16.8 \%$ seeing 11 or more. The age range of children seen was from birth to 18 years.

General practitioners saw greater numbers of children and young people for the purposes of diagnosis $\left(\chi^{2}=23.2, d f=1\right.$, $p<0.001)$, prescribing medication $\left(\chi^{2}=45.5, d f=1, p<0.001\right)$ and managing acute attacks $\left(\chi^{2}=19.3, d f=1, p<0.001\right)$, whereas nurses saw greater numbers for the purposes of education $\left(\chi^{2}=17.9, \mathrm{df}=1, \mathrm{p}<0.001\right)$ and inhaler/peak flow technique $\left(\chi^{2}=25.3, d f=1, p<0.001\right)$.

\section{Involvement of children in consultations}

Practitioners were asked to indicate in which aspects of an asthma consultation they typically involved children (see Figure 1).

Education and inhaler/peak flow technique were specific consultation goals where children were more commonly involved. Asked to describe their consultation goals and style, many practitioners stressed the importance of offering children choice;

[I] talk to them, give them opportunity to voice their experiences, concerns and preferences. Ask questions, listen to answers (ID 56, Practice ID 98).

[I involve them by] asking them about inhalers, which ones they prefer, trying placebos etc... (ID 57, Practice ID 102).

This approach seems to reflect a desire to empower children in the medical interaction and to prepare them to take responsibility for their asthma care when appropriate. Often this was done through games;

[I involve them by] making games out of peak flow etc. Making the child feel important and his/her feelings taken into account (ID 42 Practice ID 75).

I talk to [the] child as well as the adult, encourage them to be responsible for their own care where appropriate. [I] try to make asthma treatment fun rather than a chore to aid compliance (ID 14, Practice ID11).

Figure 1. Elements of the consultation that involve children and young people

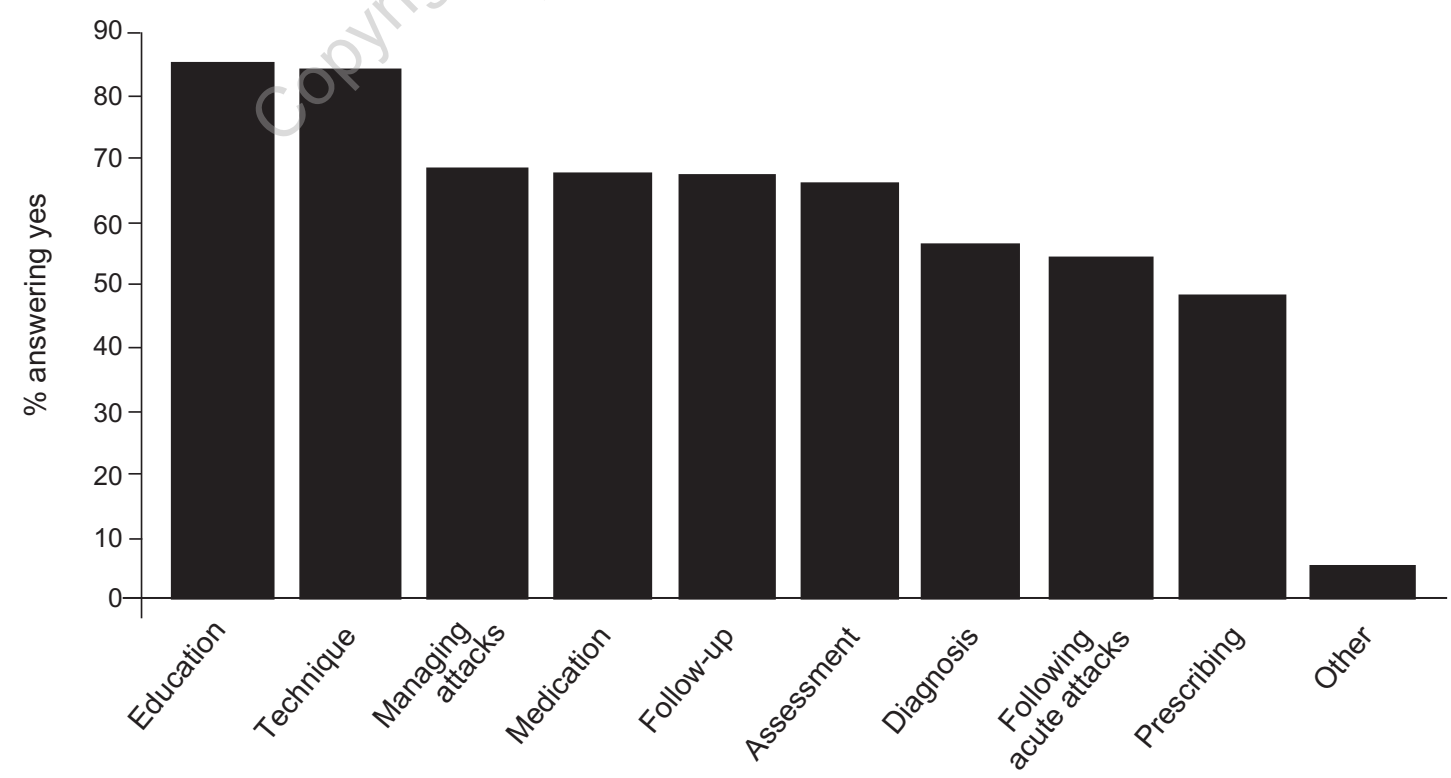


A number of respondents described their approach to promoting a child's participation in the consultation as typically talking to the child directly and checking their understanding and their personal preferences for being given information, with a view to considering the condition and associated factors from the child's perspective;

I think I always involve them, by talking to them, checking their understanding, listening to their concerns and expectations (ID 51, Practice ID 82).

[I find out] how much they already know; how much they want to know, use a stepwise graded release of information (ID 5, Practice ID 130).

Ask the child all the questions for assessment needs, asking parents/carers only when needed... (ID 49 Practice ID 78).

Some respondents described their asthma management techniques in a way which suggested a more didactic style;

Teaching about symptom changes and recognition. Look at pictures of respiratory system where appropriate. Observing inhaler technique. Leaflets to order from inhaler packs. Compliance and long term probs. Peak flow recording (ID 61, Practice ID 109).

\section{Factors affecting child involvement}

Respondents were asked to rank six factors in order of perceived importance in the context of deciding the extent to which they felt it appropriate to involve a child in their asthma consultation (see Figure 2).

\section{a) Cognitive ability}

Overall, cognitive ability was ranked as the number one factor determining the appropriate degree of child involvement in an asthma consultation. Respondents' rationale for ranking this higher than chronological age reflected a belief that understanding, maturity and language can vary in children of the same age. The sophistication of the individual child's understanding was frequently mentioned;

[Cognitive ability is] very important as this will determine the level of involvement with the child. Ways to simplify the condition to the child's level must be considered (ID 82, Practice ID 158).

b) Age

The age of a child was ranked the next most important factor. Some indicated a view that children under five would be unable to assimilate explanations directed towards them though some respondents emphasised their beliefs that children of any age can benefit from involvement;

Not appropriate if too young, most appropriate in older children (ID 66 Practice ID 111).

Always try to explain in basic terms even to young child but obviously age $<5$ to limited extent (ID25, Practice ID 41).

Just over half (55.9\%) of the respondents reported seeing children without their parents present. Ten years old was
Figure 2. Most important factors affecting involvement of children in consultations by job role.

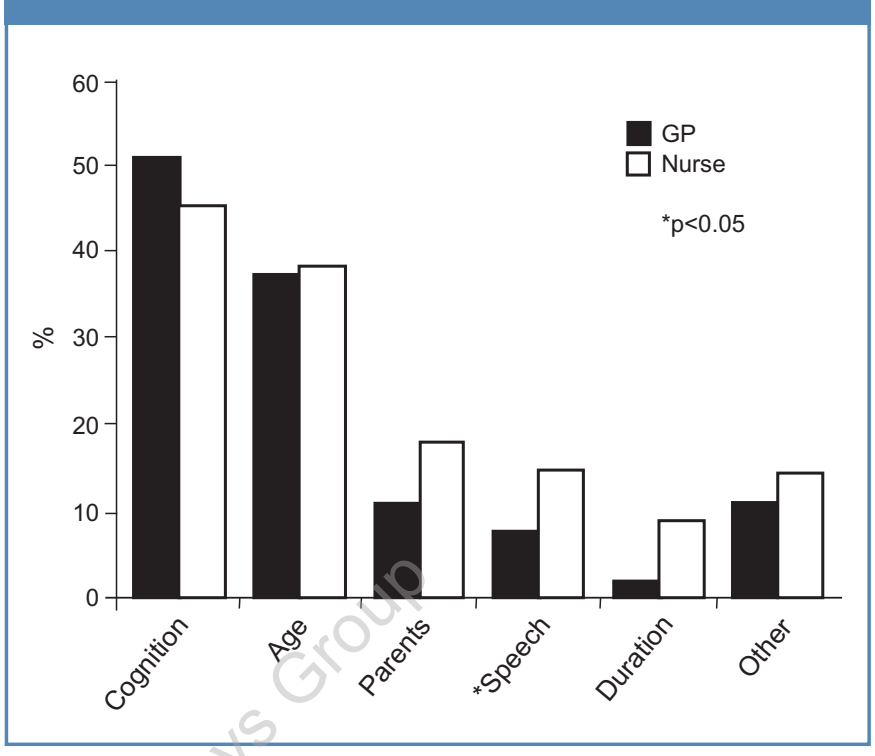

considered to be the minimum appropriate age to see a child alone, although one respondent considered five years to be appropriate. There were no differences between nurses and GPs on either seeing children alone or the minimum age that they would see children without parents present $(Z=-0.63$, $p>0.01$ ).

\section{c) Parental behaviour}

Many of the practitioners viewed parents as both potential facilitators and barriers to good asthma care, and the challenge of obtaining parental support and guidance in children's asthma management was commonly acknowledged;

Getting parents on board with treatment can have a significant impact on the child's asthma control (ID 48, Practice ID 68).

Many respondents expressed concern at the lack of support and understanding coming from some parents;

If parents [are] irresponsible then child's role even more important (ID 66, Practice ID 111).

d) Speech and language ability

The importance of communication skills was emphasised. In particular, sensitivity to a child's level of understanding and use of appropriate language were key to deciding how to involve the child. Nurses tended to rank this category higher than GPs ( $Z=-2.6, p<0.05)$;

Has a connection with cognitive ability as may not be possible for the child to communicate adequately (ID82, Practice ID 158).

\section{e) Asthma duration}

The impact of asthma duration on children's involvement in their consultations drew varying responses. Whilst some felt 
this to be irrelevant, others believed that asthma knowledge would increase with the duration of the illness;

Should involve children as much as possible when newly diagnosed. The longer they have been asthmatic, the more self-managing they should become (ID49, Practice ID 78).

Challenges

The most frequently cited difficulty in childhood asthma management was the issue of achieving concordance. Respondents described the difficulties they faced convincing children of the importance of taking medication correctly and regularly, particularly when the child felt well. In some cases respondents felt that time constraints hindered their attempts to improve concordance;

[I involve them by] talking, questioning, handing out my own 'simple guide to asthma', theoretically in choosing inhaler, checking inhaler technique, treatment plans. Time pressures means that some of the theory goes out of the window (ID 68, Practice ID 120).

\section{Disaussion}

\section{Summary of findings}

Healthcare practitioners currently have mixed approaches to child involvement, despite Department of Health policy geared to increasing children's active involvement in asthma care. ${ }^{5}$ This survey adds to our knowledge by identifying current practice and suggesting where healthcare practitioners' skills could be enhanced.

If consultations are to become more child-centred then identification of the key factors that affect involvement in consultations is critical. This study has highlighted the perceived importance of the child's age and cognitive ability, and, to a lesser extent, the effect of parental behaviour, as well as speech and language ability. Earlier reports suggest that older children are more actively involved than younger children, ${ }^{10,11,16}$ although this effect may be limited to specific elements of the consultation; GPs and parents tend to support the child's involvement in the medical history, physical assessment and review of medication, much more than diagnosis and treatment, regardless of age..$^{9,14,16}$ Our findings (Figure 1) confirm that fewer children are included in the diagnosis and prescribing components of consultations.

Respondents' views about the impact of asthma duration on the level of child involvement were by no means uniform. Our findings indicate that many practitioners assume that time spent on asthma education is required only for the newly-diagnosed. This is worrying, since there is evidence that length of time since asthma diagnosis is unrelated to asthma knowledge. ${ }^{15}$ Asthma education should be reinforced for children and young people regardless of how long they have had their condition, which ideally includes active involvement of children in their own care.

\section{Limitations}

Response rates were calculated at a practice rather than an individual level since the number of nurses in every practice was not readily available, unlike the number of GPs. Therefore, we do not have a denominator for individual response rates. The characteristics of practices who withdrew at the first stage and the individuals who chose not to participate are also unknown. A moderate practice response rate of $38.7 \%$ was achieved, despite utilising the recommendations outlined by Edwards and colleagues - such as contacting participants before sending the questionnaires and providing return envelopes ${ }^{21}$ - as well as sending extra copies of the survey and reminder e-mails.

\section{Future work}

This study represents the first stage of research investigating the complex interactions that take place in children's consultations. Further work will seek to investigate the expectations, experiences and practice of all stakeholders HCPs, children and parents - using in-depth interviews. Lessons learnt from the study of asthma management in primary care are likely to prove relevant to many other childhood conditions.

Despite the current strong 'involvement' agenda, the literature on adult decision-making in asthma management suggests that not everyone wishes to participate actively in the consultation, some preferring to take a more passive role in healthcare decisions. ${ }^{22}$ Work around individual differences that help determine the extent of responsibility children are willing and able to take ${ }^{17}$ will be a vital part of future work.

The management of asthma in children and young people is complex, but practitioners working in primary care are ideally placed to support them and their parents. Despite contemporary policy that seeks to advance the agenda of child's involvement, some practitioners find it difficult to involve children successfully in healthcare consultations. The findings of this study suggest that provision of dedicated training in child consultations may improve healthcare practitioners' communication skills and management of the consultation process, and thereby enhance achievement of concordance in relation to asthma self-management.

\section{Summary of issues}

Practitioners sometimes struggle to actively involve children in their consultations, although those who do try to offer children choice and listen to their preferences. More detailed accounts of practitioners' experiences and views, and those of children and parents need to be explored using qualitative methodology to understand the complex interactions that occur in consultations. Difficulties can be experienced when conducting postal surveys in primary care, despite efforts to maximise response rates. 


\section{Conflicts of interest}

Neither author has any conflict of interest.

\section{Acknowledgements}

We would like to thank Debra Forster for her input into the questionnaire design and study methodology, and Dr Alan Smyth and the UK Primary Care Nursing Research Network for their comments on the questionnaire. Nicola Wright and Katie Gallagher provided excellent administrative assistance, and NW also provided helpful comments on later drafts of the manuscript, as did Dr Andy Flett.

\section{References}

1. Tieffenberg J, Wood E, Alonso A, Tossutti M, Vicente M. A randomised field trial of ACINDES: a child-centred training model for children with chronic illness (asthma and epilepsy). J Urban Health 2000;77(2):280-97. doi:10.1007/BF02390539

2. Newacheck $P$, Halfon N. Prevalence, impact and trends in childhood disability due to asthma. Arch Pediatr Adolesc Med 2000;154:287-93.

3. Guevara J, Wolf F, Grum C, Clark N. Effects of educational interventions for self- management of asthma in children and adolescents: systematic review and meta-analysis. BMJ 2003;326:1308-09. doi:10.1136/bmj.326.7402.1308

4. Boylan P. Children's Voices Project. 2004, Commission for Health Improvement. p. 1- 37.

5. Department of Health, The National Service Framework for children, young people and maternity services. 2004, Department of Health: London.

6. National Asthma Campaign, Out in the open: a true picture of asthma in the United Kingdom today. The Asthma Journal 2001;6(3):1-15.

7. Asthma UK. Where next in clinical asthma research? An Asthma UK consultation on clinical asthma research strategy. 2004, Asthma UK. 1 - 19.

8. Wissow L, Roter D, Bauman L, et al. Patient- provider communication during the emergency department care of children with asthma. Medical Care 1998; 36(10):1439-50. doi:10.1097/00005650-199810000-00002

9. Tates K Meeuwesen L. Doctor-parent-child communication. A (re)view of the literature. Social Sci Med 2001;52:839-51. doi:10.1016/S02779536(00)00193-3

10. Wassmer E, Minnaar G, Adbdel Aal N, et al. How do paediatricians communicate with children and parents? Acta Paediatrica 2004;93:1501-06. doi: $10.1080 / 08035250410015079$

11. Van Dulmen AM. Children's contributions to pediatric outpatient encounters. Pediatrics 1998;102(3):563-8. doi:10.1542/peds.102.3.563

12. Tates $K$, Meeuwesen L, Elbers $E$, Bensing J. "I've come for his throat": roles and identities in doctor-parent-child communication. Child Care Health Dev 2002;28(1):109-16. doi:10.1046/j.1365-2214.2002.00248.x

13. Tates K, Meeuwesen L. 'Let Mum have her say': turn-taking in doctor-parentchild communication. Patient Educ Couns 2000;40:151-62. doi:10.1016/S0738-3991(99)00075-0

14. Pantell R, Lewis C. Talking with children: how to improve the process and outcomes of medical care. Medical Encounter 1993;10:3-7.

15. McPherson A, Glazebrook C, Forster D, James C, Smyth A. A randomised controlled trial of an interactive educational computer package for children with asthma. Pediatrics 2006;117:1046-54. doi:10.1542/peds.2005-0666

16. Tates K, Elbers E, Meeuwesen L, Bensing J. Doctor-parent-child relationships: a 'pas de trois'. Patient Educ Couns 2002;48:5-14. doi:10.1016/S07383991(02)00093-9

17. Gabe J, Olumide G, Bury M. 'It takes three to tango': a framework for understanding patient partnership in paediatric clinics. Soc Sci Med 2004;59:1071-9. doi:10.1016/j.socscimed.2003.09.035

18. Jones K, Mullee M. Proactive, nurse-run asthma care in general practice reduces asthma morbidity: scientific fact or medical assumption. Br J Gen Pract 1995;45:497-9.

19. Charlton I, Antoniou A, Atkinson J, et al. Asthma at the interface: bridging the gap between general practice and a district general hospital. Arch Dis Child 1994,70:313-18. doi:10.1136/adc.70.4.313

20. Holloway I, Wheeler S. Qualitative Research in Nursing. 2nd ed. 2004, Oxford: Blackwell.

21. Edwards P, Roberts I, Clarke M, DiGuiseppi C, Pratap S, Wentz R, Kwan I. Increasing response rates to postal questionnaires. BMJ 2002;324:1183-92. doi:10.1136/bmj.324.7347.1183

22. Caress A-L, Beaver K, Luker K, Campbell M, Woodcock A. Involvement in treatment decisions: what do adults with asthma want and what do they get? Results of a cross sectional survey. Thorax 2005;60:199-205. doi:10.1136/thx.2004.029041

\section{Available online at http://www.thepaj.org}


Appendix A. Survey of primary care consultations with children with asthma

Thank you for agreeing to participate in this survey on involving children with asthma in primary care consultations. It has four sections and should take no longer than 10-15 minutes to complete. You do not have to provide your name and your answers will remain confidential. If you have any queries, please do not hesitate to contact the lead researcher, Dr. Amy McPherson, on 01158230957 or amy.mcpherson@nottingham.ac.uk. An addressed envelope has been provided to return the questionnaire.

\section{SECTION A: You \& your practice}

1. What is your job title?

2. How long have you been working in this role? $\square$ less than a year $\square$ 1-5 years

$\square$ - 10 years $\square 10+$ years

3. Are you $\square$ Male? $\square$ Female?

4. How old are you?

$\square 20-29 . \square 40-49 \quad \square 60+$

$\square 30-39 \square 50-59$

5. Please list below all your educational and professional qualifications

6. How many full-time equivalent (fte) GPs work at the practice?

7. How many fte practice nurses/nurse practitioners work at the practice?

8. How is asthma care delivered at your practice?

$\square$ Nurse-led $\square$ GP-led $\square$ Combined GP/nurse $\square$ Other Please specify

9. Does your practice run a designated asthma clinic? $\square$ Yes $\square$ No

If not, please explain how children's asthma care is delivered.

10. How often does this take place?

11. Are you involved in children's asthma care?

$\square$ Yes $\square$ No

IF NO, STOP HERE \& PLEASE RETURN TO THE RESEARCHER AT THE ADDRESS BELOW. IF YeS, PLEASE CONTINUE. 


\section{SECTION B: Your involvement in asthma management}

12. How long have you been involved in children's asthma care?

13. Approximately how many children with asthma do you see per month?

14. What age range are they?

15. In what capacity do you provide asthma care?

$\begin{array}{lll}\square \text { Assessment } & \square \text { Following acute attacks } & \square \text { Routine follow- up } \\ \square \text { Diagnosis } & \square \text { Prescribing medication } & \square \text { Education } \\ \square \text { Managing acute attacks } & \square \text { Reviewing medication } & \square \text { Inhaler/peak flow technique }\end{array}$

$\square$ Other Please describe

16. Are you using any guidelines or protocols to inform children's asthma $\square$ Yes $\quad \square$ No care? Please specify

17. How often is the asthma care provided by your practice audited?

18. How have the results been used to change practice?

\section{SECTION C: Training and preparation for role}

19. What preparation did you receive for your role in consulting with children? Please describe any training, qualifications etc.

20. Have you undertaken the asthma diploma or other specialist respiratory training? Please specify

21. Do you undertake any continuing professional development around children's asthma care? Please specify 
22. Do you ever have the opportunity to reflect upon your consultations $\quad \square$ Yes $\quad \square$ No with children?

If yes, is this;

$\square$ Alone? $\square$ With observer feedback?

Informal discussion with colleagues

$\square$ As part of a formal training course?

$\square$ Other Please specify

23. Please list the three aspects of managing children's asthma you find most challenging

i.

ii.

iii.

\section{SECTION D: Child involvement in consultations}

24. Do you see children without their parents present?

25. At what age do you consider this to be appropriate?

26. Please rank the following factors (1-6) in terms of importance when deciding the extent to which you involve a child in their asthma consultation (where $1=$ most important), briefly explaining the importance of each:

RANK 1-6

How is this important?

Age of child

Asthma duration

Speech \& language

ability

Overall cognitive ability

Parental behaviour

Other Please specify 
Appendix A. Survey of primary care consultations with children with asthma continued

27. Is there an approximate minimum age that you routinely involve children in their asthma consultation?

28. Are there any exceptions to this? Please specify

$\square$ Yes

$\square$ No

29. Which aspects of the consultation do you involve children in?
$\square$ Assessment
$\square$ Following acute attacks
$\square$ Routine follow- up
$\square$ Diagnosis
$\square$ Prescribing medication
$\square$ Education
$\square$ Managing acute attacks
$\square$ Reviewing medication
$\square$ Inhaler/peak flow technique
$\square$ Other Please describe

30. How do you do this?

31. Is there anything else you'd like to tell us?

\begin{abstract}
Please provide your details if you wish to receive the results of this survey. We are also looking for volunteers to discuss this subject in more detail. Please provide your contact details if you would like further information about this.
\end{abstract}

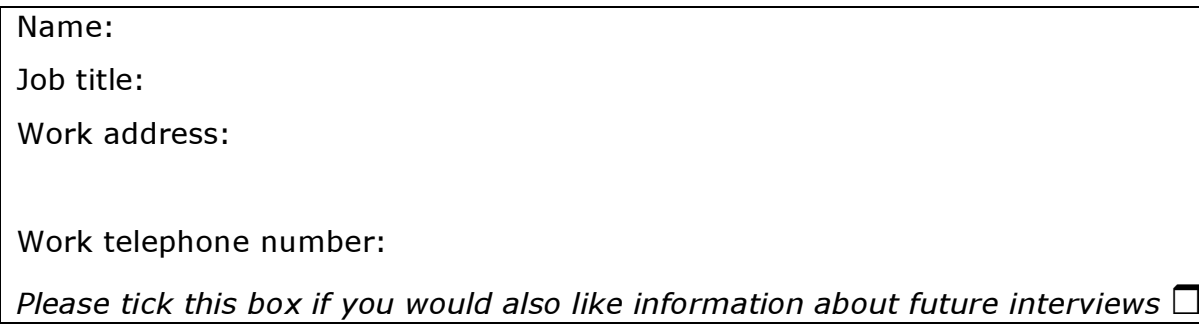

\title{
Thank you for completing this questionnaire
}

